century mineral collections considers private collections in Paris and focuses on issues of taste and aesthetics as elements in their valuation. Beretta provides a well-researched study of mineralogical traditions from the early modern collectors who classified minerals wholly on external characters, as was common with botanical and zoological collections, to those in the latter half of the eighteenth century who used chemical characters. Much of the chapter is devoted to Antoine Lavoisier, whose work was outside the old natural-history tradition and contributed to his complex theories on the history of the Earth.

Janet Browne explores how collections may provide an entrée into a higher social group the scientific community - and includes a particularly interesting account of how Darwin used his collections to break into academic circles and attain credibility.

Ana Carneiro looks in considerable detail at the lively discussion between the Swedish anatomist and palaeobotanist Alfred Nathorst, the aristocratic Gaston de Saporta and the Portuguese geologist Nery Delgado on what are now thought to be fossil trilobite tracks. Carneiro's thesis is that the interpretations of these objects by these three protagonists were influenced by their social and scientific backgrounds; this is interesting, but might well have been argued in rather less than 42 pages.

From a natural historian's viewpoint, these

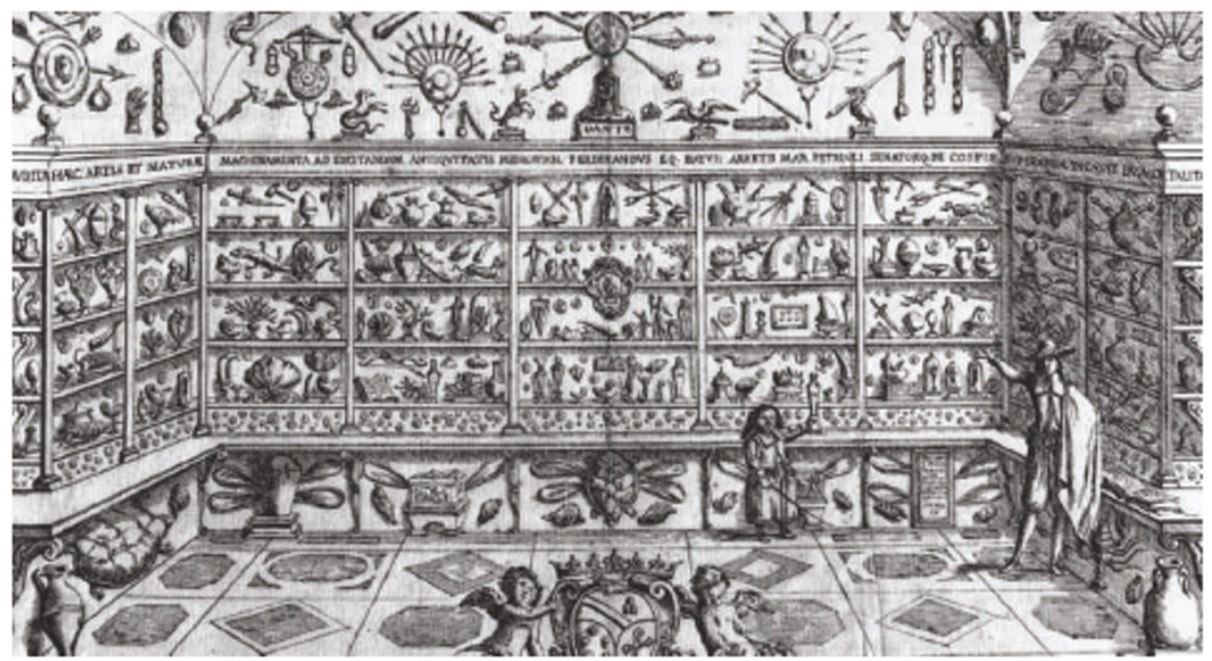

Shelf life: by the late seventeenth century, Italy was home to some remarkable collections.

papers are far removed from the more familiar accounts of how collections, collectors and specimens contributed to our knowledge of the natural world, as they also address the largely unexplored subject of the how the collections affected their collectors, an avenue of research that would reward further work. This scholarly work comprises a collection of papers that were given at a conference entitled 'From Private to Public' held in Ravenna, Italy, in June 2004. It is made accessible by the palpable enthusiasm of the authors for their subject, and is well produced with many relevant illustrations. Kathie Way iscollection managerin the Division of Higher Inver tebrates, the Natural History Museum, Cromwell Road, London SW7 5BD, UK, and honorary curator of the zoological collections of the Linnean Society of London.

MORE ON THE HISTORY OF MUSEUMS

Cabinets For the Curious: Looking Back at

Early English Museums

by Ken Arnold

Ashgate: 2006. 297 pp. $€ 47.50$

\title{
THEATRE
}

\section{A defining moment for bioethics}

\section{Biblioethics: A User's Dictionary \\ Directed by Luca Ronconi \\ Teatro Vittorio in Turin, Italy}

\section{Alison Abbott}

Luca Ronconi, one of Italy's most revered and provocative theatre directors, is at his most inspired when faced with the seemingly impossible. And the challenge of bringing a dictionary of bioethical terms to the stage is about as close to impossible as you can get. Yet Ronconi pulls it off in Biblioethics: A User's Dictionary, one of a series of five plays commissioned to promote Turin as a city of avantgarde culture on the occasion of the 2006 Winter Olympics.

Ronconi included science as one of the grand themes of contemporary humanity addressed in his series Domani, or Tomorrow. His other themes were war, history, politics and finance.

Biblioethics is not an easy play: there is no plot, just scenes that reflect on the meaning of bioethics. Ronconi disdains any technique of emotional persuasion. But he holds the attention of the audience by forcing them to participate. The theatre has been turned into a disorientating maze of small rooms separated

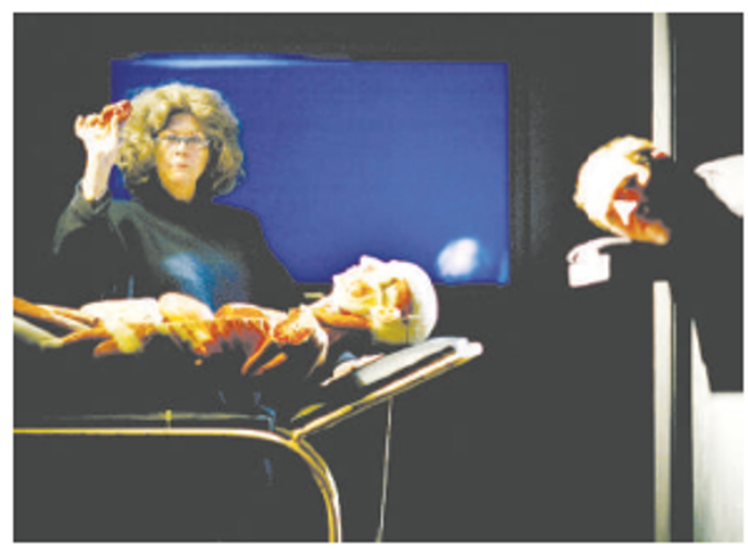

Biblioethics is helping the public come to terms with bioethics.

by thin partitions between which the audience has to move.

In the first room, the entire audience watches a video screen on which is projected the head of an actor reading out dictionary definitions of bioethical terms, beginning with the two that Ronconi considers central to bioethics: personal choice and informed consent. In the second room, actors playing representative characters - a dinician, a religious bioethicist, a secular bioethicist, and male and female students - present their points of view. They speak emotionally, but their manners are deliberately detached.

The audience then divides itself between the subsequent rooms, which are dedicated to 12 different terms, including organ donation, the Nuremberg code, euthanasia and cloning. The playlets in each room run concurrently, and viewers must focus on their chosen theme, trying not to be distracted by the voices drifting across from other rooms. They realize later that they have had the chance to see only half of the performances. Their personal choices excluded them from other options, from the sharing of other points of view.

Played out in Ronconi's hallmark monochromatic settings, the intellectual charge is animating, but the emotional charge is absent.

Biblioethics: $A$ User's Dictionary can be seen at the Teatro Vittorio in Turin until 12 March. Alison Abbott is Nature's senior European correspondent. 